\title{
Association of anatomical defects of the inferior vena cava and gonadal veins with pelvic varicose veins
}

\author{
Anastasia A. Akulova,b, Abubakari I. Sidikia , Alexandr G. Faibushevich ${ }^{a}$, \\ Zaurbek Kh. Shugusheve, , Daniil A. Maximkina, Nikolay A. Talov ${ }^{b}$, \\ Olga V. Taranenko', Galina I. Veretnic ${ }^{a}$
}

\author{
a Peoples' Friendship University of Russia, Moscow, Russia \\ b Private healthcare institution "Central clinical hospital RZD-Medicine", Moscow, Russia \\ 'FSBI "National Medical Research Centre for obstetrics, gynaecology and perinatology named after \\ academician V.I. Kulakov", Ministry of Healthcare of the Russian Federation, Moscow, Russia
}

ARTICLE INFO

Article history:

Submitted: 30. 3. 2021

Accepted: 6. 6. 2021

Available online: 30. 11. 2021
SOUHRN

Znalost klinických a anatomických odchylek pánevního žilního systému hraje významnou úlohu v diagnostice a použití katetrizačních metod u pánevních varixů. Nejvýznamnější charakteristiky gonadálních žil jsou definovány flebografickým vyšetřením dolní duté žily a pánevních žil. Aby se zabránilo prípadným komplikacím, je při endovaskulárních intervencích nutno brát tyto charakteristiky v úvahu.

(c) 2021, ČKS.

Kličová slova:

Bolest pánevních žil

Endovaskulární embolizace

gonadálních žil

Pánevní varixy

\section{ABSTRACT}

Keywords:

Endovascular embolization of

gonadal veins

Pelvic varicose veins

Venous pelvic pain

Knowledge of the clinical and anatomical variations of the pelvic venous system plays a significant role in the diagnosis and transcatheter methods of treatment of pelvic varicose veins. The most important characteristics of gonadal veins are identified by phlebography of the inferior vena cava and pelvic veins. These characteristics should be taken into account during endovascular interventions in order to avoid possible complications.

Pelvic varicose veins (PVV) is a disease characterized by dilatation of ovarian veins and pelvic venous plexuses. Nonetheless, when there is retrograde blood flow, ovarian venous insufficiency can be encountered in patients with normal venous diameter $(4-5 \mathrm{~mm})$. According to various authors, the incidence of PVV among females is approximately $30 \%$ which shows the gravity of this medical and social problem. Per several studies, $10-70 \%$ of PVV patients also develop varicose veins of the lower extremities: $^{1}$ in $10-62 \%$ of cases, the cause of recurrent lower limbs varicosities is pelvio-perineal reflux. ${ }^{2,3}$

The diagnosis and treatment of PVV remains the focus of attention among phlebologists and vascular surgeons, because there are still no generally accepted recommendations that dictate treatment algorithms for patients with unusual venous anatomies as well as clear indications and contraindications for surgical cure. ${ }^{4}$ Phlebography is currently the standard diagnostic method for PVV. In the normal pelvic venous system, the right and left common iliac veins empty into the inferior vena cava (IVC) at the level of the lower edge of the L5. ${ }^{3}$

Typically, inferior vena cava (IVC) is valveless, retroperitoneal, and on the right of the abdominal aorta. The ascending lumbar vein which joins the paired lumbar veins empties directly into IVC. The longer left ovarian vein (LOV) usually drains into the left renal vein, while the shorter right ovarian vein (ROV) on the other hand empties directly into IVC. ${ }^{5,6}$

Normally, the LOV forms anastomoses with the inferior mesenteric vein, which in $49 \%$ of women drain into the 
middle segment of the LOV. However, the ROV is more variable: it anastomosizes with the superior mesenteric vein in $60 \%$ of cases, drains into the infrarenal segment of IVC, or in $30 \%$ of cases, empties into the confluence of the right renal vein (RRV) and the IVC. In $10 \%$ of cases, it drains directly into the intrarenal branches of the right renal vein. ${ }^{7}$

The first pelvic phlebography ever performed was by Guillaume and Beau in 1954. It showed tortuous and dilated gonadal veins without pelvic congestion syndrome (PCS). The anatomy of the female pelvic venous system differs significantly from person-to-person and is quite complex - especially with respect to the various venous plexuses surrounding the vagina and uterus. ${ }^{8}$ Whilst the cystic plexus has valves, the uterine and the pampiniform plexuses are valveless. ${ }^{9}$

In $6-15 \%$ of women, the left gonadal veins are valveless. Meanwhile, in $41 \%$ of patients, congenital gonadal venous insufficiency occurs on the left and on the right in $46 \% .^{10}$ As a rule, in most patients, the development of PCS is facilitated by both congenital defects of the tributaries of the IVC and the normal anatomical ovarian blood flow. ${ }^{11}$

Per the results of many studies, $17 \%$ of people have abnormal renal veins, ${ }^{12,13} 0.5-30 \%$ of whom have multiple renal veins (most often of the right side). ${ }^{12}$ In $26-29 \%$ of these people, the renal veins are double, whereas triple renal veins occur in $5-9.7 \%$ of them. ${ }^{14}$ Anomalies of LRV have been found in only $5 \%$ of observed patients. ${ }^{12}$ A good example is a case of four right renal veins with multiple renal arteries. ${ }^{15}$

Apart from the above-described defects in the development of renal veins, other structural anomalies include circumaortic LRV, which has quite a rare incidence $\left(0.3-5 \%\right.$ of cases). ${ }^{16}$ Observations by N. Drabe et al. (2001) showed that the prevalence of retroaortic LRV was $0.8-7 \% .{ }^{17,18}$ According to M. Izumiyama et al. (1997), retroaortic LRV develops when the ventral arch of the aortic collar regresses, whilst the dorsal arch persists to form LRV. The ventral portion develops between supracardinal veins, and the posterior portion originates from the supracardinal venous anastomosis. ${ }^{19}$ The clinical manifestations of the retroaortic position of LRV are impaired venous outflow and development of renal venous congestion, resulting in ovarian varicose veins. ${ }^{20}$

From a surgical point of view, in order to avoid recurrence of PVV, it is very important to take into account the possibility of 1-2 lower lumbar veins or double gonadal veins draining into the LRV. This anatomical variation occurs in $37-65 \%$ of females. ${ }^{19}$ Moreover, for a successful phlebography, it is necessary to know all the possible anatomical defects of LRV drainage into the IVC. Anomalies of LVR are classified according to:

\section{Number of veins}

I) presence of accessory renal veins;

II) double left renal vein:

a) with drainage of adrenal vein into the upper left renal vein;

b) with drainage of adrenal vein into the lower left renal vein;
III) incomplete bifurcation of left renal vein;

IV) multiple left renal veins.

\section{Retroaortic left renal vein}

\section{Extracaval drainage}

I) into the iliac vein;

II) into the hemiazygos vein;

III) into the iliac and hemiazygos veins (after splitting);

IV) into the precaval venous plexus.
4. Vertebral level
I) high - above the L1;
II) low - below L2.

\section{Venous pathologies \\ I) stenosis; \\ II) presence of valves; \\ III) other.}

Futhermore, J.K. Nam et al. (2010) described 4 anatomical variations of drainage of a retroaortic LRV into IVC (Fig. 1). ${ }^{20}$ Though most of the anatomical variations of pelvic veins have no functional significance, they can pose difficulties during femoral vessels catheterization or pelvic surgeries. ${ }^{21}$

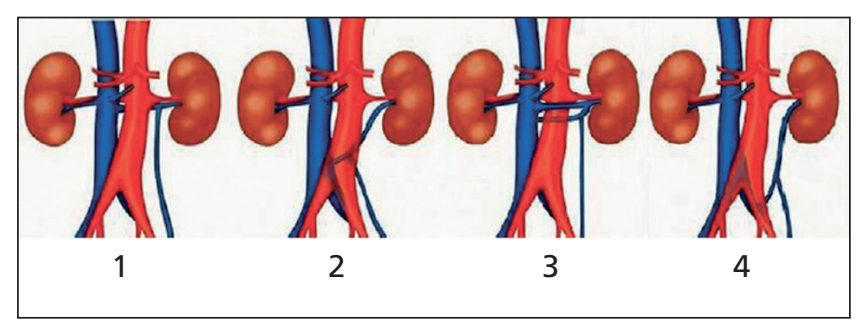

Fig. 1 - Possible forms of retroaortic left renal vein drainage: type 1 - directly into the inferior vena cava (typical at L1-L2); type 2 inferiorly into the inferior vena cava (below L1-L2); type 3 - circumaortically into the inferior vena cava; type 4 - into the left common iliac vein.

Mack Shin et al. (2014) in a retrospective study to determine the prevalence of congenital defects of iliac veins reviewed the multidetector computed tomography of 2,488 patients. They presented their findings in a schematic drawing (Fig. 2). A normal IVC is rightsided, i.e., it lies to the right of the aorta. A left-sided IVC is a congenital defect whereby IVC is located on the left of aorta with LRV crossing aorta anteriorly to join RRV and the right-sided suprarenal segment of IVC (Fig. 3).22 The prevalence of a left-sided IVC is $0.2-0.5 \% .{ }^{23}$

A double IVC is a rare occurrence, found in $0.6-2.3 \%$ of study subjects. ${ }^{24,25} \mathrm{M}$. Itoh et al. (2001) explained that a double IVC forms when left supracardinal veins persist (Fig. 4). ${ }^{26}$ Also, aplasia of the hepatic segment of IVC and its communication with the azygos vein is seen in $0.6 \%$ of instances. ${ }^{26}$ This defect of IVC deserves much attention since under unfavourable conditions, (trauma, surgery, or a history of infection) it can be complicated by deep vein thrombosis and chronic venous insufficiency. ${ }^{27}$ 


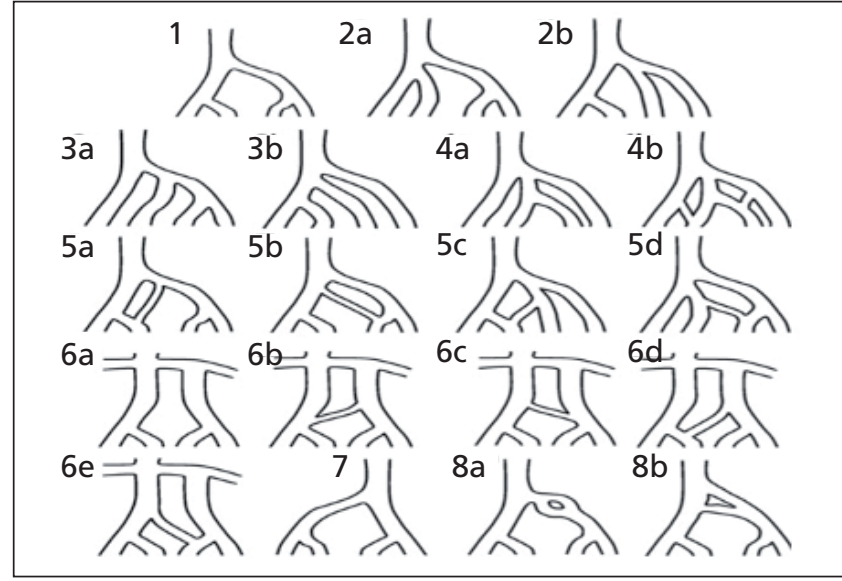

Fig. 2 - Schematic presentation of pelvic venous variations. Type 1: normal iliac venous connection $-\mathbf{7 9 . 1 \%}$ of study subjects; type 2 : high joining of the internal iliac vein to the ipsilateral external iliac vein $-7.8 \%$; type 3 : internal iliac vein joins the contralateral common iliac vein - $2.3 \%$; type $4 a$ : internal iliac veins form a common trunk $-0.4 \%$; type $4 b$ : internal iliac veins form a common trunk and communicating veins between the ipsilateral external iliac vein and the internal iliac vein $-0.5 \%$; type $5(a, b)$ : communicating vein between the internal iliac vein and contralateral common iliac vein $-6.9 \%$; type $5(c, d)$ : communicating vein between the internal iliac vein (or tributaries for it) and the contralateral internal iliac vein $-0.9 \%$; type $6 a$ : double inferior vena cava without a connecting vein $-0.2 \%$; type $6(b, c)$ : double inferior vena cava with a connecting vein between the common iliac veins - $0.5 \%$; type 6 (d, e): double inferior vena cava with a connecting vein between the common iliac vein and internal iliac vein $-0.2 \%$; type 7 : left inferior vena cava $-0.1 \%$; type $8 \mathrm{a}$ : segmental duplication of the common iliac vein $-0.2 \%$; type $8 \mathrm{~b}$ : duplication of the common iliac vein with separate drainage to the inferior vena cava and contralateral iliac vein $-0.2 \%$

\section{Case report. Right ovarian vein dilatation, most probably due to inferior vena cava transposition}

A 27-year-old nulligravid patient presents with disparenuria, dysmenorrhea, and pain in the right iliac region. She had these symptoms for over 3 years. The pain intensified during physical activities and was refractory to phlebotonics. She is on hormonal replacement therapy (YAZ). Her previous medical history includes autoimmune thyroiditis.

An MRI revealed a left-sided infrarenal segment of IVC, signs of stenosis in the middle and proximal segments of the right common iliac vein, and dilated right ovarian vein (12 mm), ascending lumbar vein (10-12 mm), parametric venous plexus (12 $\mathrm{mm})$, arcuate vein $(9 \mathrm{~mm})$. The IVC above its bifurcation was $20 \times 16.5 \mathrm{~mm}$ (Fig. 4). She was diagnosed with pelvic varicose veins and pelvic congestion syndrome. A phlebography of IVC and pelvic veins by femoral access with a $5 \mathrm{~F}$ Cobra 1 catheter (Cook Medical, Bloomington, IN, USA) revealed the same findings. A superselective embolization of the right ovarian vein with a Penumbra Coil 35 was performed (Fig. 5).

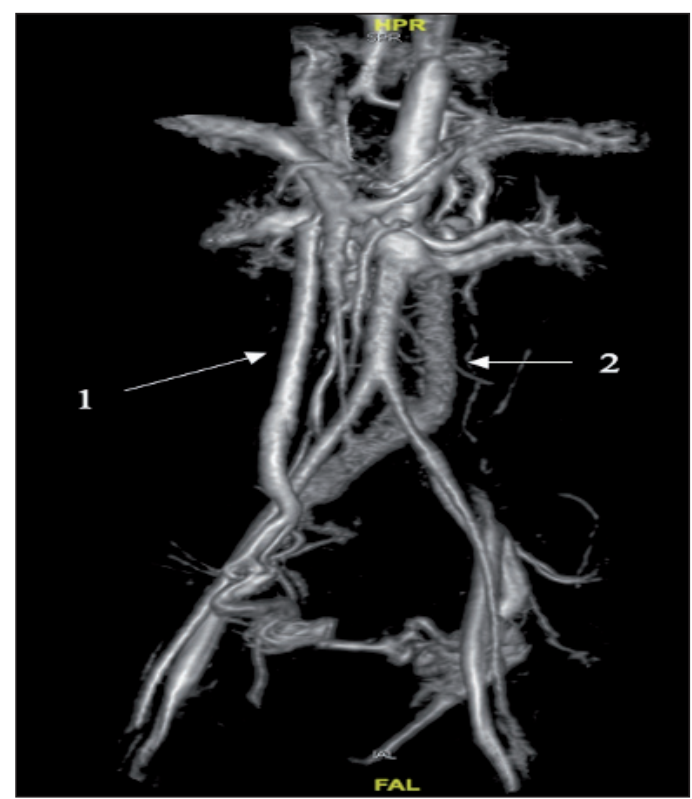

Fig. 4 - Non-contrast MRI phlebography of IVC and pelvic veins. 1 - dilated right ovarian vein; 2 - inferior vena cava.

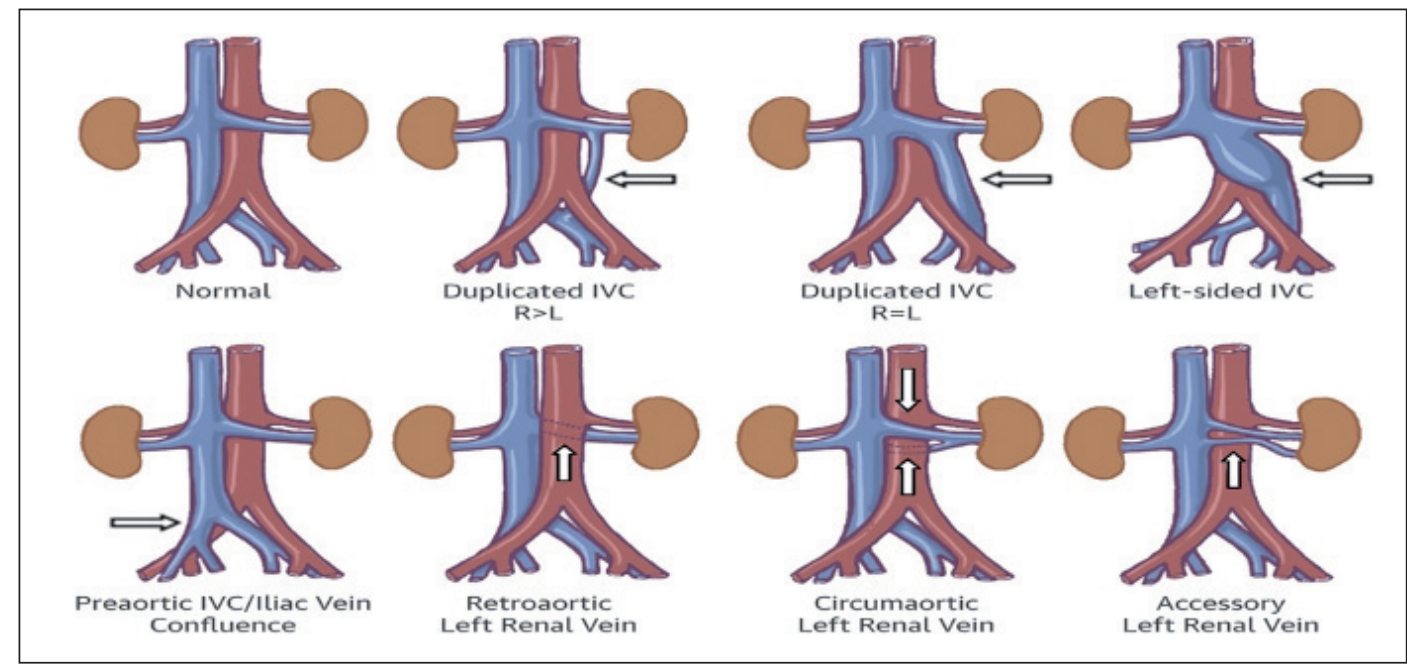

Fig. 3 - Variations of left-sided IVC. IVC - inferior vena cava; L - left; R - right. Adapted with permission from Truty et al. Ann Vasc Surg 2007;21:186-197. 


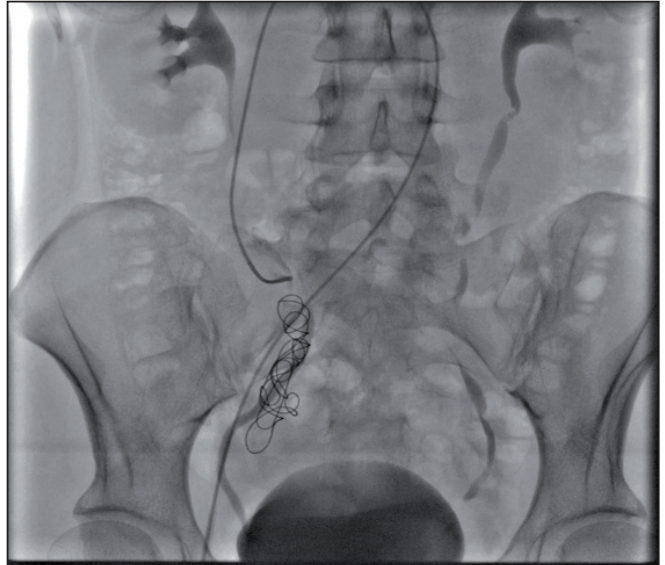

Fig. 5 - Phlebography and embolization of right ovarian vein.

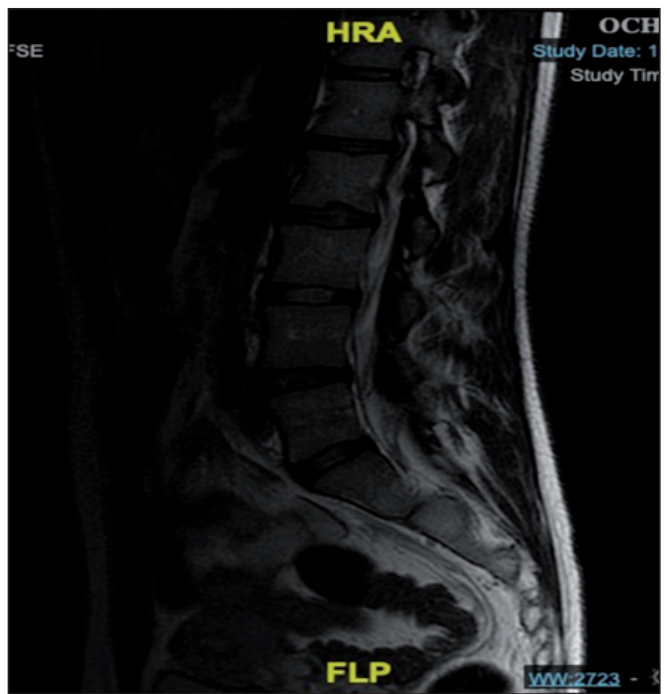

Fig. 6 - MRI of lumbar-sacral vertebrae.

A week after the procedure, the patient experienced significant symptoms reduction, but starting having pains in the area of the coil embolization. Abdominal and transvaginal ultrasounds did not reveal a perforation nor an ulceration in this area. An MRI of the lumbar-sacral vertebrae showed osteochondrosis of L1-S1, spondylarthrosis and prolapse of the L1-L2 intervertebral disc (Fig. 6).

She was referred to a neurologist and after treatment, the pain regressed. A repeated IVC and pelvic veins phlebography 2 months after the procedure showed right ovarian vein obliteration and no pelvic congestion syndrome. This case report indicates that an IVC anomaly (transposition) can be the reason of a late diagnosis.

\section{Conclusion}

Therefore, congenital defects of IVC and its tributaries is a risk factor for the development of chronic pelvic venous insufficiency. A retroaortic LRV may present clinically as obstructed venous outflow and congestive renal venous hypertension, which culminates in the development of ovarian varicose veins..$^{20,28}$ Also, anaplasia of the hepatic segment of IVC can cause symptoms of peripheral venous thrombosis and chronic venous insufficiency, which in $50 \%$ of instances are bilateral..$^{29}$

The high prevalence of multiple right renal veins is associated with the peculiarities of development of the abdominal right and left venous system. Whereas RRV develops from multiple mesonephros veins, LRV originates from left subcardinal and supracardinal venous anastomosis. ${ }^{30}$ Variations of IVC and its tributaries development can have serious clinical effects (from PVV to gonadal and iliac venous thrombosis), and so, should be taken into consideration during interventional procedures. Careful interpretation of results of non-invasive diagnostic methods could help prevent serious mistakes in patient management.

\section{Reference}

1. Whiteley AM, Taylor DC, Dos Santos SJ, et al. Pelvic venous reflux is a major contributory cause of recurrent varicose veins in more than a quarter of women. J Vasc Surg Venous Lymphat Disord 2014;2:411-415.

2. Asciutto G, Mumme A, Asciutto KC, et al. Pelvic vein incompetence influences pain levels in patients with lower limb varicosity. Phlebology 2010;25:179-183.

3. Lasry JL, Coppe G, Balian E, Borie H. Pelvi-perineal venous insufficiency and varicose veins of the lower limbs: duplex Doppler diagnosis and endoluminal treatment in thirty females. J Mal Vasc 2007;32:23-31.

4. Antignani PL, Lazarashvili Z, Monedero JL, et al. Diagnosis and treatment of pelvic congestion syndrome: UIP consensus document. Int Angiol 2019;38:265-283.

5. Lopez AJ. Female pelvic vein embolization: indications, techniques, and outcomes. Cardiovasc Intervent Radiol 2015;38:806-820.

6. Black CM. Anatomy and physiology of the lower-extremity deep and superficial veins. Tech Vasc Interv Radiol 2014;17:68-73.

7. Koo S, Fan CM. Pelvic congestion syndrome and pelvic varicosities. Tech Vasc Interv Radiol 2014;17:90-95.

8. Beckett D, Dos Santos SJ, Dabbs EB, et al. Anatomical abnormalities of the pelvic venous system and their implications for endovascular management of pelvic venous reflux. Phlebology 2018;33:567-574.

9. Seddon J. The management of varicose veins. Br J Surg 1973;60:345-347.

10. Ahlberg NE, Bartley O, Chidekel N. Right and left gonadal veins. Anatomical and statistical study. Acta Radiol Diagn (Stockh) 1966;4:593-601.

11. Kamina $P$, Chansigaud JP. Functional anatomy of pelvic veins in women. Phlebologie 1989;42:363-384.

12. Ali-El-Dein B, Osman $Y$, Shokeir AA, et al. Multiple arteries in live donor renal transplantation: surgical aspects and outcomes. J Urol 2003;169:2013-2027.

13. Mathews R, Smith PA, Fishman EK, Marshall FF. Anomalies of the inferior vena cava and renal veins: embryologic and surgical considerations. Urology 1999;53:873-880.

14. Satyapal KS, Kalideen M, Haffejee AA, et al. Left renal vein variations. Surg Radiol Anat 1999;21:77-81.

15. Watarai Y, Kubo K, Hirano T, et al. Intravenous digital subtraction angiography and helical computed tomography in evaluation of living renal donors. Int J Urol 2001;8:417-422.

16. Urban BA, Ratner LE, Fishman EK. Tree-dimensional volume-rendered CT angiography of the renal arteries and veins: normal anatomy, variants and clinical applications. Radio-graphics 2001;21:373-386. 
17. Drabe N, Zund G, Hoerstrup SP, et al. Surgical management of retro-aortic left renal vein in combined abdominal aortic and coronary surgery. Vasa 2001;30:135-137.

18. Mandal AK, Cohen C, Montgomery RA, et al. Should the indications for laparascopic live donor nephrectomy of the right kidney be the same as for the open procedure? Anomalous left renal vasculature is not a contraindication to laparoscopic left donor nephrectomy. Transplantation 2001;71:660-664.

19. Izumiyama M, Horiguchi M. [Two cases of the retroaortic left renal vein and a morphogenetic consideration of the anomalous vein]. Kaibogaku Zasshi 1997;72:535-543. Japanese.

20. Nam JK, Park SW, Lee SD, Chung MK. The clinical significance of a retroaortic left renal vein. Korean J Urol 2010;51:276-280.

21. Chen $\mathrm{H}$, Emura $\mathrm{S}$, Nagasaki $\mathrm{S}$, Kubo KY. Double inferior vena cava with inter iliac vein: a case report and literature review. Okajimas Folia Anat Jpn 2012;88:147-151.

22. Jiménez $R$, Morant $F$. The importance of venous and renal anomalies for surgical repair of abdominal aortic aneurysms. In: Grundmann RT (Ed.) Diagnosis, screening and treatment of abdominal, thoracoabdominal and thoracic aortic aneurysms. In Tech 2011; 269-275.

23. Huntington GS, McLure CF. The development of the veins in the domestic cat (felis domestica) with especial reference, 1 ) to the share taken by the supracardinal vein in the development of the postcava and azygous vein and 2) to the interpretation of the variant conditions of the postcava and its tributaries, as found in the adult. Anatomical Record 1920;20:1-29.

24. Mathews R, Smith PA, Fishman EK, Marshall FF. Anomalies of the inferior vena cava and renal veins: embryologic and surgical considerations. Urology 1999;53:873-880.

25. Ashley DW, Gamblin TC, Burch ST, Solis MM. Accurate deployment of vena cava filters: comparison of intravascular ultrasound and contrast venography. J Trauma 2001;50:975981.

26. Itoh $\mathrm{M}$, Moriyama $\mathrm{H}$, Tokunaga $\mathrm{Y}$, et al. Embriological consideration of drainage of the left testicular vein into the ipsilateral renal vein: analysis of cases of a double inferior vena cava. Int J Androl 2001;24:142-152.

27. Gayer G, Luboshitz J, Hertz M, et al. Congenital anomalies of the inferior vena cava revealed on $\mathrm{CT}$ in patients with deep vein thrombosis. AJR Am J Roentgenol 2003;180:729-732.

28. Hayashi $\mathrm{M}$, Kume $\mathrm{T}$, Nihira $\mathrm{H}$. Abnormalities of renal venous system and unexplained renal hematuria. J Urol 1980;124:12-16.

29. Fernandes $\mathrm{R}$, Israel $\mathrm{RH}$. Isolated azygos continuation of the inferior vena cava in the elderly. Respiration 2000;67:229-233.

30. Watarai $Y$, Kubo K, Hirano T, et al. Intravenous digital subtraction angiography and helical computed tomography in evaluation of living renal donors. Int J Urol 2001;8:417-422. 